\title{
IMPLEMENTASI MANAJEMEN BANDWIDTH MENGGUNAKAN METODE QUEUE TREE (STUDI KASUS PADA UNIVERSITAS PANCASILA)
}

\author{
Martini $^{1}$ \\ Sistem Informasi \\ Universitas Bina Sarana Informatika \\ Jakarta \\ martini.mtn@bsi.ac.id
}

\author{
Elly Mufida ${ }^{2}$ \\ Teknik Komputer \\ Universitas Bina Sarana Informatika \\ Jakarta \\ elly.elm@bsi.ac.id
}

\author{
Dickshan Aryo Krisnadi ${ }^{3}$ \\ Teknik Informatika \\ STMIK Nusa Mandiri \\ Jakarta dickshanaryo@gmail.com
}

\begin{abstract}
Penggunaan teknologi yang semakin berkembang khusunya di bidang pendidikan menjadi kebutuhan yang sangat komplek untuk menunjang kelancaran operasional pendidikan. Universitas Pancasila adalah salah satu perguruan tinggi yang telah banyak meluluskan mahasiswa terbaiknya membutuhkan teknologi informasi dalam menunjang seluruh kegiatan operasinal kampus. Hampir seluruh aktivitas membutuhkan jalur komunikasi atau koneksi jaringan yang efisien dan fleksibel agar terjalin efektivitas dalam melakukan segala tindak pertukaran informasi data. Dengan pembagian bandwidth yang tidak merata serta tumpang-tindihnya aliran paket data menyebabkan penurunan aktivitas pengguna jaringan di lingkungan Universitas Pancasila, sehingga menyebabkan koneksi pada setiap pengguna menjadi tidak stabil baik pada jaringan internet maupun intranet. Dengan digunakannya metode queue tree transaksi paket data akan lebih terstruktur, karena paket data akan diarahkan berdasarkan koneksi asal, sehingga mengurangi adanya antrian berlebih di dalam router yang akan menyebabkan penundaan pengiriman paket data ke interface yang dituju. Pengaturan trafik ini dapat mengoptimalkan trafik data dengan cara menggunakan salah satu fitur yang ada di Routerboard Mikrotik yaitu Mangle, yang dapat memberikan aturan protokol mana yang melewati jalur intranet dan protokol mana yang melewati jalur intranet. Queue tree juga dapat mengatasi pemerataan distribusi bandwidth pada setiap pengguna yang berada pada satu bagian yang sama.
\end{abstract}

Kata kunci: Queue tree, Routerboard Mikrotik, Mangle

\section{PENDAHULUAN}

Kebutuhan akan teknologi khususnya dalam jaringan komputer di lingkungan Universitas Pancasila sangatlah penting untuk mendukung segala kegiatan yang ada, seperti proses kegiatan belajar mengajar, pengolahan dan transaksi data, kebutuhan administrasi, bertukar informasi bahkan dalam hal kebutuhan sosial dan sebagainya. Oleh sebab itu optimalisasi pada jaringan komputer sangatlah penting agar bisa menunjang kegiatan tersebut secara bersamaan tanpa mengurangi kualitas satu sama lain. Dibutuhkan pengaturan akses informasi dan pengaturan pemakaian bandwith dengan menggunakan metode tertentu akan menjadi solusi yang bisa

Identify applicable sponsor/s here. (sponsors) diambil untuk mengatasi permasalahan yang dihadapi di kampus. Pengaturan tersebut dapat diterapkan pada router mikrotik di jaringan komunikasi kampus yang dicatat pada
IP-Tables yang berisikan IP address, protokol, ataupun konten, yang mengatur otorisasi pengguna jaringan dan apakah jaringan diperbolehkan atau tidak untuk diakses.

Dengan adanya tumpang-tindih aliran paket data menyebabkan penurunan aktivitas kinerja dari sumber daya manusia di lingkungan kampus. Berdasarkan hal tersebut, dibutuhkan sebuah pengaturan mengenai trafik data pada jalur yang terpisah antara internet dan intranet. Oleh karena itu dibutuhkan suatu pengaturan akses data dan pemakaian bandwith pada masing-masing bagian dalam penggunaan jaringan komunikasi. Queue tree adalah metode yang digunakan pada penelitian ini untuk mengatasi permasalahan pembagian bandwidth baik pada penggunaan internet maupun intranet.

\section{LANDASAN TEORI}

\section{A. Konsep Jaringan}

Menurut (Stalling: 429) jaringan komunikasi didefinisikan sebagai fasilitas yang menyediakan layanan transfer data di antara perangkat yang terhubung ke jaringan. Jaringan dapat berupa internet atau intranet. Jaringan internet adalah kumpulan jaringan komunikasi yang saling terhubung melalui bridge dan atau router. Sedangkan jaringan intranet adalah internet yang digunakan oleh satu organisasi yang menyediakan aplikasi internet utama. Intranet beroperasi dalam organisasi untuk tujuan internal dan dapat eksis dengan cara terisolasi, internet mandiri, atau mungkin memiliki tautan ke internet.

\section{B. Topologi Jaringan}

Dalam konteks jaringan komunikasi menurut (Stalling: 332) istilah topologi mengacu pada cara di mana endpoint, atau station, berada pada jaringan yang saling berhubungan. Di dalam topologi jaringan digambarkan hubungan antar komponen-komponen jaringan, seperti komputer server, komputer client, switch, router, dan pengkabelan.

\section{Manajemen Bandwidth}

Pada dasarnya manajemen bandwidth (Towidjojo, 2014) merupakan suatu metode pengendalian arus lalu lintas paket data pada sebuah jaringan komputer dengan menggunakan Router yang berfungsi sebagai alat untuk menjalankan metode manajemen bandwidth. Dengan adanya manajemen bandwidth maka pembagian besaran bandwidth/troughput akan merata, sehingga tidak akan ada antrian paket data di dalam jaringan komputer yang berakibat keterlambatan pengiriman atau penerimaan paket data. 
Alat manajemen trafik yang banyak digunakan adalah token bucket yaitu cara mengkarakterisasi dan mengelola lalu lintas data yang memiliki tiga keunggulan (Stalling: 640):

1. Sumber trafik yang banyak dapat didefinisikan dengan mudah dan akurat dengan skema token bucket.

2. Skema token bucket memberikan deskripsi singkat tentang beban yang akan ditimbulkan oleh aliran, memungkinkan layanan untuk menentukan dengan mudah sumber daya kebutuhan.

3. Skema token bucket memberikan parameter input untuk mengatasi fungsi-fungsi.

Menurut (Kurnia, 2017) mengatakan bahwa HTB (Hierarchical Token Bucket) merupakan salah satu metode antrian yang adil dan bertujuan menerapkan fungsi link sharing untuk setiap client. Pada HTB terdapat TBF (Token Bucket Filter) yang berfungsi sebagai alat estimator yang sangat mudah diimplementasikan dikarenakan hanya dengan menggunakan parameter rate $\mathrm{HTB}$ dapat mengeset rate bandwidth yang akan diberikan kepada client. Kelebihan HTB yang lainnya yaitu memiliki parameter ceil yang akan mengatur bandwidth pengguna di antara base rate dan nilai ceil rate-nya. Parameter ceil ini juga merupakan alternatif HTB dalam membagi bandwidth ke client dikarenakan HTB akan memberikan bandwidth yang tersisa apabila bandwidth keseluruhan tidak digunakan oleh client dengan syarat bandwidth tersisa yang akan diberikan masih dibawah nilai rate ceil yang diset

\section{Qиеие Tree}

Queue Tree menurut (Malik, Aksara \& Yamin, 2017) adalah konfigurasi queue yang bersifat one way (satu arah), ini berarti sebuah konfigurasi queue hanya akan mampu melakukan queue terhadap satu arah jenis traffic. Jika sebuah konfigurasi queue pada Queue Tree ditunjukan untuk melakukan quеие terhadap bandwidth upload, demikian pula sebaliknya. Sehingga untuk melakukan queue terhadap traffic upload dan download dari sebuah komputer client, harus membuat 2 (dua) konfigurasi queue.

\section{METODE PENELITIAN}

Metode yang digunakan dalam penulisan ini dilakukan dalam beberapa tahap, diantaranya:

\section{A. Analisa Kebutuhan}

Manajemen bandwidth dengan menggunakan metode Queue Tree adalah sebagai salah satu kebutuhan di Universitas Pancasila dalam memberikan solusi terhadap keluhan dari semua pihak terkait dalam penggunaan jaringan komputer di dalam setiap aktivitasnya selama berada di lingkungan kampus. Dengan demikian, metode Quеие Tree dapat memberikan efektifitas dan optimalisasi dalam penggunaan jaringan komputer guna menunjang efisiensi penggunaan biaya dan infrastruktur.

\section{B. Desain}

Identify applicable sponsor/s here. (sponsors)

Pada penelitian ini telah dilakukan pengamatan dan mempelajari desain topologi jaringan beserta penggunaan bandwidth yang ada di Universitas Pancasila yang pada akhirnya ditemukan beberapa masalah dalam komunikasi jaringan. Kemudian diusulkan penggunaan metode queue tree dan penyesuaian topoginya dan membuat alokasi kecepatan data berdasarkan protokol, port, dan alamat IP. Paket Tracer digunakan untuk menggambarkan skema topologi pada jaringan yang sedang berjalan dan jaringan usulan untuk memudahkan pengaturan trafik data pada jalur komunikasi.

\section{Testing}

Dalam analisa testing menggunakan alat bantu software seperti packet tracer, virtualbox, routerOS dan bandwidth test untuk melakukan ujicoba jaringan baik pada jaringan berjalan ataupun jaringan usulan yang masing-masing digunakan untuk:

a. Packet Tracer adalah aplikasi yang digunakan penulis untuk elakukan pengujian koneksi secara logic.

b. Virtualbox \& RouterOS digunakan untuk membuat disain konfigurasi bandwidth management dengan queue tree yang menjadi usulan.

c. Bandwidth Test fitur yaitu Mangle yang terdapat di sistem operasi pada Routerboard Mikrotik untuk mengukur besaran Troughput/Bandwidth pada sebuah aliran paket data di setiap interface.

\section{Implementasi}

Implementasi dilakukan dengan memanfaatkan fasilitas komputer dan jaringan yang sudah berjalan milik Universitas Pancasila, kemudian menerapkan metode queue tree yang terdapat pada fitur Routerboard Mikrotik.

\section{HASIL DAN PEMBAHASAN}

Manajemen bandwidth menggunakan metode queue tree yang digabungkan dengan metode HTB (Hierarchical Token Bucket) adalah sistem manajemen bandwidth lanjutan dari simple queue yang digunakan oleh kampus. Disebut lanjutan karena metode queue tree digunakan untuk menunjang model jaringan yang sudah terbangun dengan kompleks, serta cocok untuk model jaringan yang ada pada kampus, karena sifat metode queue tree yang lengkap dan dapat diatur sesuai kebutuhan. HTB memungkinkan membuat struktur queue berjenjang dan menentukan relasi antara parent dengan child, ataupun antar sesama child.

Media yang digunakan pada topologi jaringan yang sudah dibangun oleh Universitas Pancasila yaitu fiber optik sebagai media backbone jaringan dan sudah mendukung Fast Gigabyte Ethernet pada tiap interface Ethernet, karena media jaringan tersebut secara langsung mendukung skema jaringan dalam mengoptimalkan trafik jaringan yang ada pada Universitas Pancasila.

Kualitas backbone yang sudah didukung oleh media fiber optik sangat berguna karena kapasitas bandwidth yang disanggupkan fiber optik sangatlah besar, bisa mencapai lebih dari 1Gbps. Dengan skema jaringan usulan yang dirancang, maka akan menjadi pengaruh yang sangat besar untuk mengatasi permasalahan yang sering terjadi. 


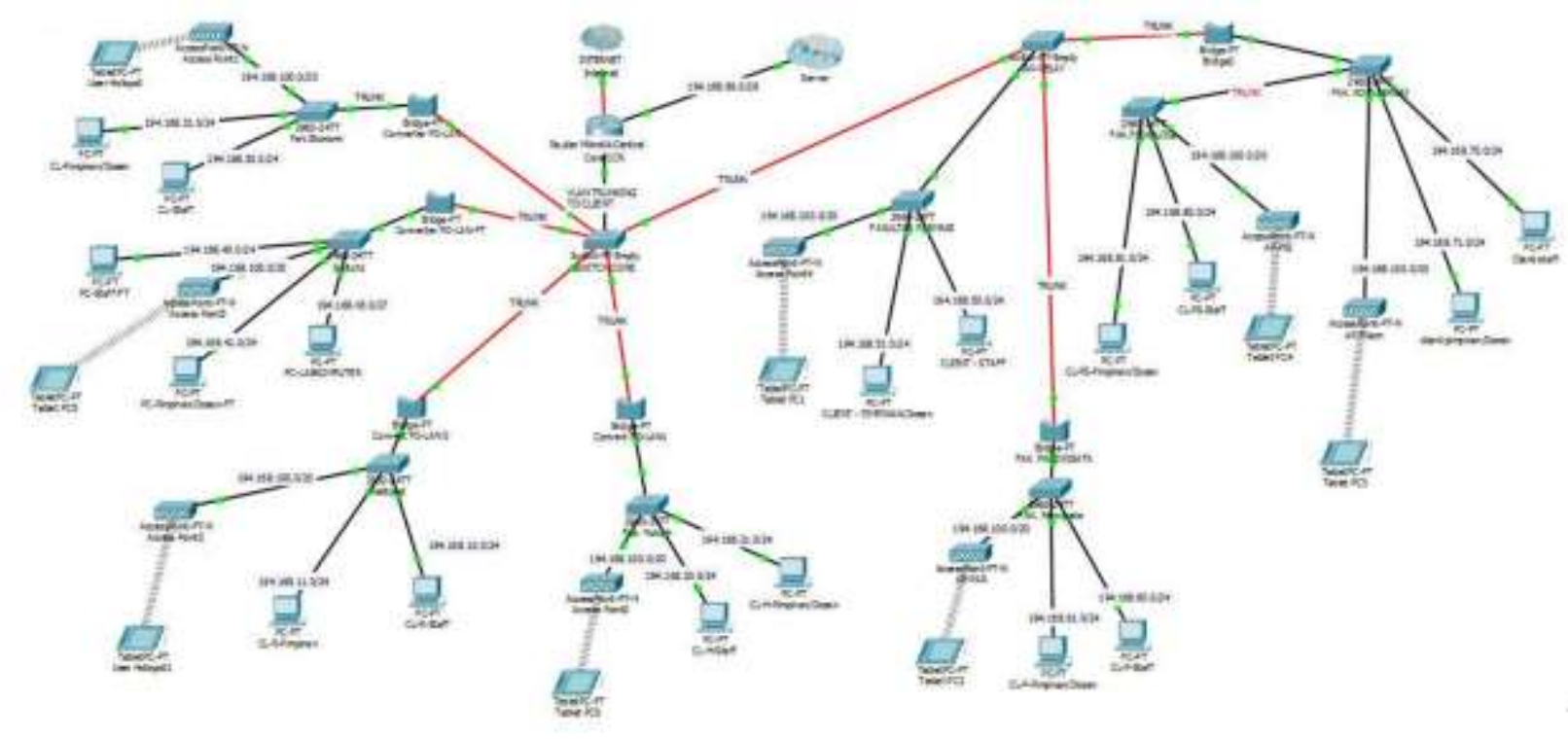

Gambar.1. Skema Jaringan Usulan Universitas Pancasila

\section{A. Keamanan Jaringan}

Pada keamanan jaringan, metode queue tree merupakan suatu metode yang memberikan sistem keamanan berupa fleksibilitas, karena dalam membatasi bandwidth dengan menggunakan queue tree, teknisi bisa memberikan konfigurasi berdasarkan port protocol, jenis trafik, ataupun arah trafik yang akan dituju. Konfigurasi ini dilakukan melalui aturan yang ada pada fitur mikrotik, yaitu mangle.

Dengan mangle inilah aktifitas aliran jaringan akan diatur sesuai kebutuhan yang diperlukan. Pada keamanan jaringan yang berkaitan dengan manajemen bandwidth, maka fitur mangle sangat berperan penting untuk mengatur jenis trafik apa yang akan boleh diterima atau dikirim oleh sistem. Ketika mangle mengatur kebutuhan yang lebih spesifik, maka dalam membatasi besaran bandwidth sangat cocok dengan menggunakan metode queue tree. Penulis mencoba menganalogikan contoh pengaturan yang akan dibuat dengan menggunakan mangle seperti berikut:

add action=rark-routing chain=prerouting disabled=yes dst-address=1

203.89.146.8/23 dst-port=48300-46828 new-routing-nark=rou-wan1 ।

passthrough=yes protocol=udp

Gambar.2. Konfigurasi Mangle

Maksud dari gambar di atas adalah proses routing dengan melewati port protocol yang sudah diatur. Ketika paket data yang menuju ke network ip 203.89.146.0/23 dengan melalui tujuan port protocol 40000-40020 dengan menggunakan jalur protocol UDP, maka paket data tersebut akan diterima dan diarahkan ke alamat yang dituju, sebaliknya ketika ada paket data yang bukan melalui jalur tersebut, maka paket data tersebut akan ditolak untuk melanjutkan pengiriman paket data yang dituju. Hal ini merupakan salah satu langkah keamanan untuk mengatasi adanya penyalahgunaan jaringan, seperti snipping ataupun hacking.

\section{B. Pengujian Jaringan}

Metode queue tree memberikan solusi terhadap permasalahan jaringan yang sering terjadi, karena dalam metode tersebut semua paket haruslah diberikan tanda tujuan kemana paket itu berjalan, hal ini mengurangi resiko antrian terhadap paket-paket yang tidak ditandai oleh mangle serta mengurangi adanya antrian yang berlebih. Peran yang sangat vital dalam menggunakan metode quеие tree adalah peranan mangle pada Router Mikrotik, queue tree memberikan tekanan secara langsung kepada mangle agar dapat selektif memilih koneksi atau paket data yang melewati router.

Berikut adalah gambar proses pengiriman paket yang dilakukan dalam simulasi pengujian pemberian beban internet bersamaan dengan memberikan beban bandwidth terhadap jalur intranet:

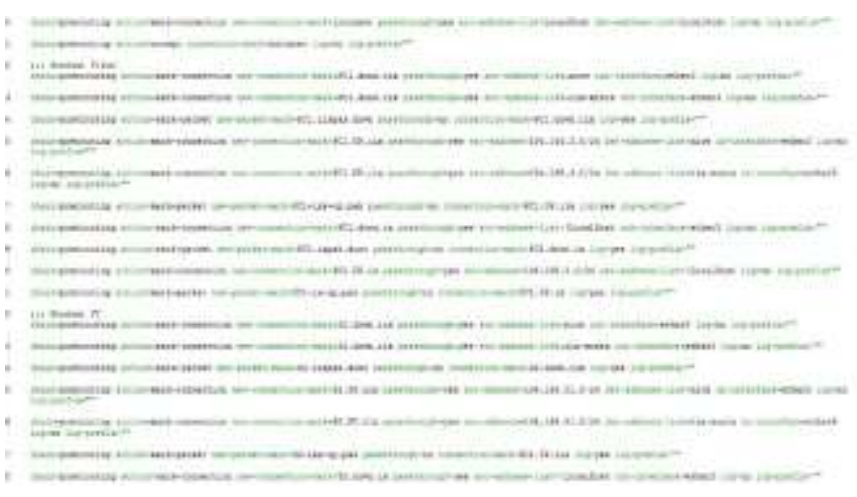

Gambar.3. Konfigurasi Mangle untuk Metode Queue Tree

Proses pada quеие tree sebelum diteruskan langsung ke parent-parent yang ada adalah menunggu proses seleksi mangle selesai dalam memilih paket, lalu mengirimkannya sesuai paket yang sudah ditandai. Pada proses inilah di dalam queue tree akan terjadi antrian pada setiap parent yang sudah diseleksi oleh mangle, sehingga akan mengaktifkan aturan dari queue tree yang mengontrol kapasitas transaksi tersebut 
dalam jumlah yang sudah ditentukan. Berikut adalah contoh gambar

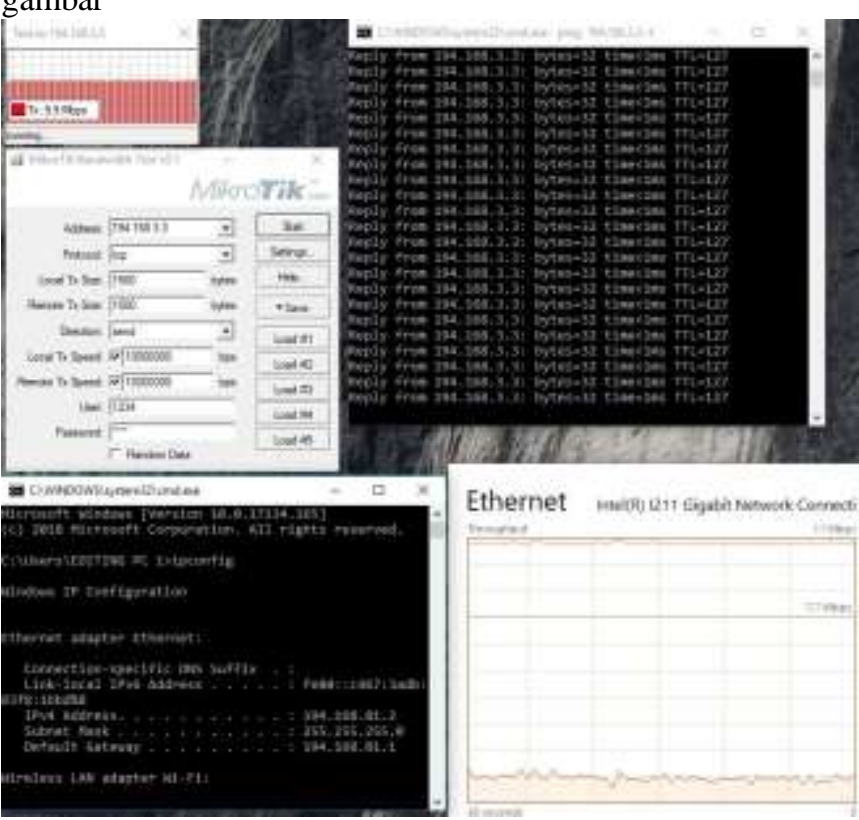

proses kerja queue tree yang mengontrol kapasitas transaksi yang melewati suatu parent:

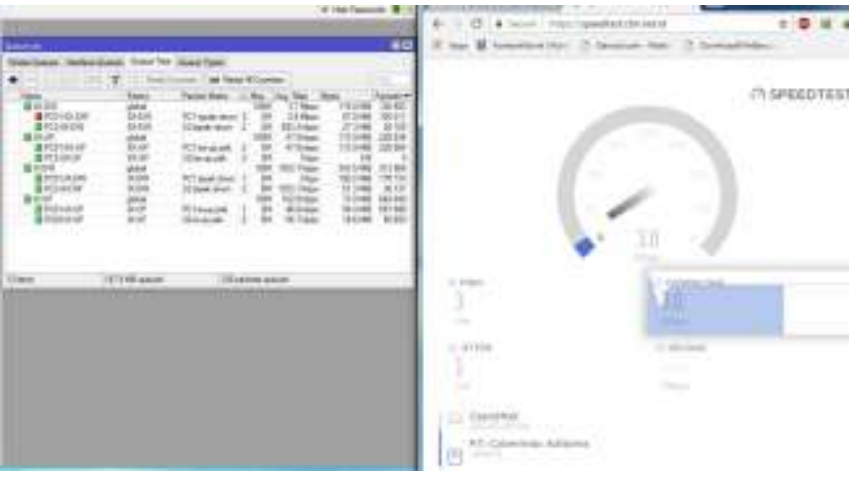

Gambar.4. Test Koneksi Jalur Download

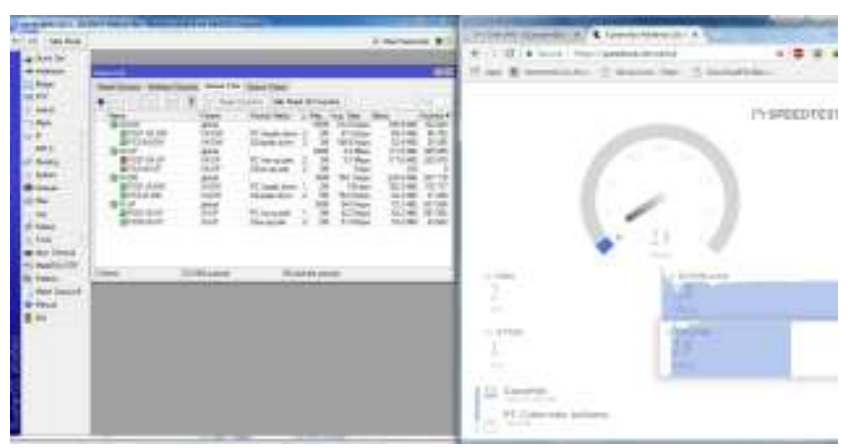

Gambar.5. Test Koneksi Jalur Upload

Dari hasil simulasi pada gambar 4 dan gambar 5 membuktikan bahwa mangle digunakan untuk memisahkan antar jalur berjalan dengan baik, ketika pengguna melakukan transaksi paket data ke koneksi internet yang diberikan. Kemudian untuk simulasi pengujian bandwidth pada jalur intranet adalah pada gambar berikut:

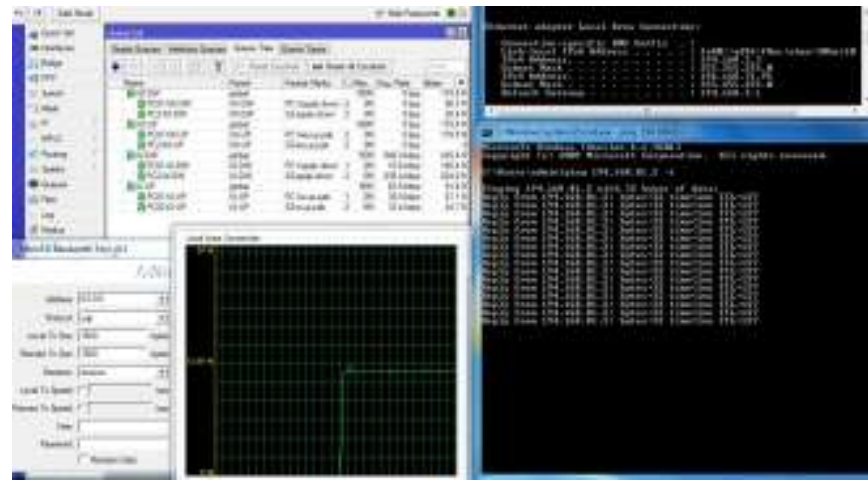

Gambar.6. Pengujian Bandwidth Intranet pada PC2

Gambar.7. Pengujian Bandwidth Intranet pada PC1

Pengujian intranet di atas menjelaskan bahwa komputer dengan ip address 194.168.81.2 mengirimkan beban bandwidth dengan menggunakan aplikasi bandwidth test sebesar 10Mbps ke komputer dengan ip address 194.168.3.3. Terlihat bahwa koneksi tersebut tidak melewati antrian terlebih dahulu, karena limit dari queue tree tersebut tidak adanya pembatasan bandwidth yang sedang dilakukan antara kedua komputer tersebut.

Hal ini membuktikan bahwa terdapat perbedaan dan perubahan ke arah yang lebih baik dari kondisi jaringan awal yang ada pada Universitas Pancasila. Terlihat adanya kebutuhan melaui jalur internet dan jalur intranet sangat besar, dan pemisahan antar jalur internet dan intranet sangat diharapkan oleh seluruh civitas akademika Universitas Pancasila sehingga bisa memberikan kualitas jaringan yang efektif tanpa adanya tumpang-tindih koneksi.

\section{KESIMPULAN}

Setelah mempelajari, menganalisa dan melakukan pengujian terhadap kondisi jaringan yang ada pada Universitas Pancasila, dapat diambil kesimpulan sebagai berikut:

1. Aktivitas yang menggunakan infrastruktur jaringan komunikasi tentunya memerlukan pengaturan bandwidth yang baik agar semua pengguna jaringan dapat melakukan kegiatannya tanpa ada gangguan mengenai antrian trafik atau bottleneck, dan kesenjangan bandwidth yang kurang efisien pada jaringan komunikasi. Manajemen bandwidth memberikan dampak positif bagi pengguna dan juga bagi kualitas jaringan agar mendapatkan perlakuan yang merata dalam penggunaan bandwidth.

2. Manajemen bandwidth dengan menggunakan metode queue tree memberikan dukungan maksimal dalam penggunaan jaringan komputer terhadap pengguna yang dalam melakukan pekerjaannya selalu memakai prinsip multitasking agar pekerjaan tersebut cepat diselesaikan

3. Dengan menggunakan metode queue tree akan mengurangi adanya dampak koneksi yang lambat dikarenakan antrian yang besar, karena queue tree 
memerintahkan untuk mensama-ratakan bandwidth dalam satu parent atau induk besaran bandwidth yang sudah ditentukan.

4. Dengan menggunakan queue tree, trafik yang ada pada jaringan akan lebih efektif dan terjamin keamanannya karena transaksi paket data akan lebih tepat sasaran.

\section{REFERENSI}

Kurnia, D. (2017). Analisis QoS pada Pembagian Bandwidth Dengan Metode Layer 7 Protocol, PCQ, HTB dan Hotspot di SMK Swasta Al-Washliyah Pasar Senen. CESS (Journal of Computer Engineering System and Science), Vol 2, No.2, pp. 102-111

Malik, A., Aksara, L.F., \& Yamin, M. (2017). Perbandingan Metode Simple Queues dan Queues Tree Untuk Optimasi Manajemen Bandwidth Menggunakan MikroTik (Studi Kasus: Pengadilan Tinggi Agama Kendari). Jurnal SemanTIK, Vol.3, No.2, pp. 1-8.

Silitonga, P., \& Morina, I.S. (2014). Analisis QoS (Quality Of Service) Jaringan Kampus Dengan Menggunakan Microtic Routerboard ( Studi Kasus:
Fakultas Ilmu Komputer Unika Santo Thomas S.U), Jurnal TIMES, vol. III, no. 2, pp. 19-24.

Sofana, I. (2010). Cisco CCNA \& Jaringan Komputer. Bandung: Informatika.

Stalling, W. (2014). Data and Computer Communications. $10^{\text {th }}$ Edition. New Jersey: Pearson Prentice Hall.

Suryanto. (2018). Pengaturan Pemakaian Bandwidth Dan Akses Jaringan. Jurnal Ilmu Pengetahuan dan Teknologi Komputer. vol. 3, no. 2, pp. 167-172.

Towidjojo, R. (2014). Mikrotik Kung Fu: Kitab 3 Kitab Manajemen Bandwidth. Jakarta: Jasakom. 